\title{
A sequential extraction procedure for manganese and its application to marine sediments
}

\author{
WYTZE K. LENSTRA, THILO BEHRENDS, ROBIN \\ KLOMP, FERIKE MOLEMA AND CAROLINE P. SLOMP \\ Utrecht University \\ Presenting Author: w.k.lenstra@uu.nl
}

Manganese (Mn) is a key element in marine systems and its dynamics can affect the cycling of many elements, such as iron $(\mathrm{Fe})$, phosphorus $(\mathrm{P})$ and carbon $(\mathrm{C})$. The biogeochemical impact of $\mathrm{Mn}$ depends on its form in the sediment. For example, Mn oxides can be involved in the oxidation of dissolved $\mathrm{Fe}(\mathrm{II})$, organic matter and methane. Mn(II)-phosphates and P-bearing Mn carbonates may promote the burial of $\mathrm{P}$ in sediments. While sequential extractions are widely used to discern between various sediment forms of $\mathrm{Fe}, \mathrm{P}$ and sulfur, no sequential extraction procedure is currently available to investigate the solid phase speciation of $\mathrm{Mn}$.

In this study, an extraction procedure that is widely used for the speciation of Fe in sediments, is calibrated for Mn using a range of standards. The standards consist of various $\mathrm{Mn}$ oxides, Mn carbonates, Mn(II)-phosphate minerals, Mn sulfides and clays. We show that the extraction procedure allows us to separate most of the Mn phases, and is especially successful in distinguishing between $\mathrm{Mn}$ oxides, Mn carbonates and $\mathrm{Mn}$ associated with pyrite.

Additionally, we applied the sequential extraction to a range of marine sediments with varying bottom water redox conditions. The results show that, in sediments deposited in euxinic bottom waters, $\mathrm{Mn}$ is mainly present in Mn carbonates and bound in clays and pyrite, in approximately equal amounts. In sediments deposited in periodically euxinic and hypoxic bottom waters, $\mathrm{Mn}$ carbonates dominate over the other two fractions and small but variable amounts of $\mathrm{Mn}$ oxides are also observed. In sediments deposited in oxygenated bottom waters, Mn oxides, Mn-rich vivianite-type minerals and $\mathrm{Mn}$ carbonates dominate and no pyrite bound $\mathrm{Mn}$ is observed. We also find evidence for the presence of $\mathrm{Mn}$ oxides below the sulfate methane transition at one location, suggesting that at this site, Mn oxides could potentially contribute to the anaerobic oxidation of methane. 